\title{
Measuring dysgraphia: a graded-difficulty spelling test
}

\author{
D.M. Baxter ${ }^{1}$ and E.K. Warrington \\ National Hospital, Queen Square, London WC1 3BG, UK \\ 'Present address: Kemsley Brain Injury Division, St Andrew's Hospital, Billing Road, \\ Northampton NN1 5DG, UK
}

Correspondence to: E.K. Warrington at above address

\begin{abstract}
In this paper we describe the construction of a graded-difficulty spelling test for adults consisting of two alternative forms each containing 30 words (GDST, Forms A and B). The spelling test, together with background tests of verbal and non-verbal skills, was administered to 100 control patients with orthopaedic injuries. The two forms of the spelling test were highly correlated (0.92). Spelling was highly correlated with reading $(0.75,0.77)$ and moderately correlated with vocabulary $(0.57)$ and naming $(0.39,0.40)$. There was no correlation between spelling skills and non-verbal reasoning. The test was validated in a group of 26 patients with left hemisphere and 20 patients with right hemisphere lesions. Spelling was shown to be lateralized to the left hemisphere and there appeared to be a shift in scores of the left hemisphere group towards the lower quartile, with $65 \%$ of the left hemisphere group falling within this band. The most severe spelling impairments were invariably associated with other language disorders but a number of dissociations were documented at spelling levels falling between the 5th and 25th percentile band. Two patients with left hemisphere lesions $(8 \%)$ were identified as having selective dysgraphias. The lack of overlap between the anatomical sites of the two patients with specific lexical dysgraphia argues against a single site for this type of dysgraphia and argues for further refinement of this classification of spelling disorder.
\end{abstract}

Keywords: Spelling test - Adults - Acquired - Dysgraphia

\section{INTRODUCTION}

An impairment in written spelling is commonly observed in patients with aphasia. The identification of spelling disorders in patients with neurological impairments is dependent upon the sensitivity of the assessment measures and whether the investigator clearly distinguishes between disorders of spelling and disorders of writing. For instance Goodglass and Geschwind (1976) claimed that a degree of dysgraphia is present in all cases of aphasia without exception. By contrast, Weigl and Fradis (1977) estimated that just under a half or $44 \%(15 / 34)$ of their sample of aphasic patients had an impairment in writing single words to dictation in the absence of difficulties with copying.

Such estimates contrast with the low prevalence of patients with a relatively selective disorder of spelling occurring in the context of preserved language skills. Basso et al. (1978) identified only two such cases in their consecutive series of 500 patients with left hemisphere involvement $(0.4 \%)$. A further two cases had both spelling and reading impairments and a further three patients had spelling difficulties in association with mild fluent aphasia. How far these estimates would predict cases with isolated spelling dysgraphia in a "phonetically irregular" language such as English remains an open question.

As with other cognitive skills, there is a range of language and reading abilities in the normal population and it is not unreasonable to assume that such a range will also exist for spelling. Although it is known that measures such as vocabulary and reading are highly correlated with other verbal and non-verbal skills (Nelson and McKenna, 1975), little is known about the relationship of spelling with other skills in the normal adult population. Because of the lack of normative data for the adult population, the significance of an individual's level of spelling may be lost and minor degrees of impairment missed in high-level patients; premorbid writing samples are often not available. The increasing number of publications of individual cases documenting relatively selective spelling dysgraphias, emphasizes the importance of incorporating a measure of spelling in any comprehensive neuropsychological assessment (e.g. Shallice, 1981; Baxter and Warrington, 1985; Goodman and Caramazzo, 1986). 
In this study we describe the construction of a graded-difficulty spelling test (GDST) which allows for the measurement of individual differences in spelling skills. Two alternative forms were standardized on 100 normal subjects and subsequently administered to a group of 26 patients with left hemisphere involvement and 20 patients with right hemisphere involvement. The aims of the investigation were two-fold:

(1) To examine the relationship between spelling skills and reading, verbal and non-verbal reasoning skills in the normal population and thus to evaluate the feasibility of using spelling as a predictor of other skills and vice versa.

(2) To explore the incidence of spelling deficits in patients with unilateral cortical lesions and validate the test in a population of lesioned patients.

\section{PILOT STUDY}

A pool of 40 pairs of words was chosen on the basis of the similarity of the phonemic structure, word length and word frequency (Thorndike and Lorge, 1944). All words were orthographically "ambiguous" in so far as they could plausibly be written in more than one way and still retain the sound of the target item. Pre-pilot work with hospital employees suggested the word pairs covered a wide range of difficulty levels. From the pre-pilot work, it was apparent that there was a small group of people who had never acquired spelling skills. Several subjects were not only unable to write words from dictation but were also impaired in their level of reading. As the spelling test was designed to measure levels of deterioration after neurololgical damage in a premorbidly literate population, it was considered appropriate to focus on subjects with literacy skills that fell within the average range or above.

The word pairs were administered to 26 orthopaedic patients at a London teaching hospital, aged between 20 and 55 years. On the basis of the results of this pilot study, the selection of items was further refined and 30 matched pairs were selected and arranged in order of difficulty to form the basis of two alternative forms of an adult GDST (Forms A and B). A cut-off score of five consecutive errors before discontinuing the test was established on the basis that 25 out of 26 subjects in the pilot study met this criterion: one subject passed one further item on the basis of this cut-off.

\section{STANDARDIZATION OF THE GDST}

\section{Subjects}

The normal control group consisted of 50 male and 50 female in-patients in the orthopaedic wards of a London district hospital (Brook Hospital). Ten male and 10 female subjects were tested in each of five age ranges, from 20 to 69 years. A wide range of occupations were included in this sample, the largest group being semi-skilled (33\%). Six were left-handed for writing. All patients were tested if they were judged by the ward sister to be well enough to complete the testing session lasting between 30 and $60 \mathrm{~min}$. Patients were excluded if they were on medication other than antibiotics or if they had a history of intracerebral disease or of long-term diabetes. They were also excluded if they had a history of a head injury or of epilepsy or had been educated outside the normal English educational system. Patients were included only if they achieved a score of 8 or more correct on the Nelson Adult Reading Test (NART; Nelson, 1983). A score of 7 or less would exclude individuals below the 30th pencentile on the Wechsler Adult Intelligence Scale (WAIS; IQ 92 and below) and below the 8th percentile on the WAIS-R (IQ 77 and below).

\section{Procedure}

Each control subject was tested individually in a quiet room or at the bedside with screens drawn for privacy. The purpose of the research was explained to each subject and each was screened on the NART. In addition to the two alternative forms of the spelling test, subjects completed a selection of baseline tests including measures of verbal and non-verbal skills. The order of test presentation was randomized with the exception that the spelling tests were never given as the first item. A brief description of the tests is given below.

Non-verbal reasoning (Short Matrices). A selection of 20 items [items B1, 2, 4, 6, 8, 10, 12: $\mathrm{C} 1,3,5$, 7, 9, 11: D2, 4, 6, 8, 10, 11, 12 (practice items : B7, 11)] taken from the Standard Progressive Matrices (Raven, 1958) was presented in a booklet form. Control subjects were required to complete the items within a $20 \mathrm{~min}$ period. Two practice items were given to ensure that the control subjects understood the nature of the task and feedback was given in respect to any errors. After the practice items were completed, no further help was given.

Verbal expressive skills. The WAIS Vocabulary subtest (Wechsler, 1955) was administered as a meas- 
TABLE I. Characteristics of the normal subjects: means, standard deviations on each test with significance levels for tests of normality and gender differences $(n=100)$

\begin{tabular}{lccc}
\hline & $\begin{array}{c}X \\
\text { S.D. } \\
\text { (range) }\end{array}$ & $\begin{array}{c}\text { K-S } \\
\text { (normal) } \\
z\end{array}$ & $\begin{array}{c}\text { M-W } \\
\text { (gender) } \\
z\end{array}$ \\
\hline Vocabulary & 49.55 & 0.63 & -1.45 \\
& 11.61 & $p=0.82$ & $p=0.15$ \\
McKenna & $(23-71)$ & & \\
(naming) & 21.03 & 0.21 & -2.69 \\
& 4.14 & $p=0.10$ & $p=$ \\
Short Matrices & $(8-29)$ & & $0.01^{\star \star}$ \\
& 12.96 & 1.36 & -1.08 \\
NART & 3.31 & $p=0.05^{\star}$ & $p=0.28$ \\
(no. correct) & $(3-19)$ & & \\
& 24.12 & 0.44 & -0.03 \\
Schonell & 9.11 & $p=0.99$ & $p=0.98$ \\
& $(8-47)$ & & \\
Spelling A & 89.26 & 1.60 & -1.07 \\
& 8.42 & $p=0.01^{\star \star}$ & $p=0.28$ \\
Spelling B & $(59-100)$ & & \\
& 19.65 & 1.23 & -1.46 \\
& 6.02 & $p=0.10$ & $p=0.14$ \\
Spelling A + B & $(4-28)$ & & \\
& 19.49 & 1.34 & -1.48 \\
& 6.49 & $p=0.06$ & $p=0.14$ \\
& $(1-29)$ & & \\
\hline & 39.59 & 1.29 & -1.56 \\
& 12.29 & $p=0.07$ & $p=0.12$ \\
& $(5-57)$ & & \\
\hline
\end{tabular}

K-S, Kolmogorov-Smirnov test; M-W, Mann-Whitney Utest.

Two-tailed level of significance: ${ }^{*} p=0.05 ;{ }^{*} p=0.01$

ure of verbal comprehension and expression. The Graded Naming Test (McKenna and Warrington, 1983) was administered as a measure of naming vocabulary. (Both tests were administered according to standard procedures.)

Reading skills. The National Adult Reading Test (Nelson, 1983) and the Schonell Graded Reading Vocabulary Test (Schonell and Schonell, 1950) were administered as measures of single-word reading and were presented according to standard procedures.

Spelling skills. The revised selection of the two 30 word lists which formed the basis of the two alternative forms of the GDST were administered (see Appendix 1). The order of the two forms of the spelling test was alternated such that half the subjects completed List A before completing List B and half completed List B before completing List A. Each word was presented in the context of a sentence and the target word was clearly spoken both before and after the sentence was given. Further repetitions of the target word were given if needed. All subjects were required to write the words from both lists. Three were unable to use their writing hand because of orthopaedic injuries. For these subjects, the examiner wrote their oral spellings in full view and spontaneous corrections were allowed. Each spelling list was discontinued after five consecutive failures.

\section{ANALYSIS OF RESULTS OF THE STANDARDIZATION STUDY}

\section{Baseline measures}

The means, standard deviations and ranges for each test are given in Table I. The Kolmogorov-Smirnov one-sample test was used to test the normality of the distribution of scores in each of the tests and the Mann-Whitney U-Test was used to test for gender differences (SPSS programmes; Nie et al., 1975). The $z$-scores and the probability levels are also given in Table I. The distribution of scores on the Short Matrices Test and the Schonell Reading Test was significantly different from normal. The Schonell Test appeared to have a ceiling effect, indicating poor discrimination at higher reading levels. The Short Matrices Test did not appear to have sufficient items at higher levels to allow for a more equal distribution of scores in this literate sample. A significant effect of gender was found in the Graded Naming Test $(\bar{X}$ males $=22.30 ; \bar{X}$ females $=19.76)$, a finding which has not been documented on this test in other studies. No gender differences were observed in any other test.

Spearman-rank correlation coefficients were calculated between the raw scores on each of the tests and with age; the results are given in Table II. There was a significant negative correlation between scores on the Matrices items and with age: age did not correlate with performance on any other test. As would be expected, the two reading tests were highly correlated and there was a moderately high correlation between the two reading tests (NART and Schonell) and with both the WAIS Vocabulary subtest and with naming vocabulary.

\section{GDST}

The means, standard deviations and ranges on each form (A and B) of the spelling test are given in Table I. The distribution of scores on both versions of the two alternative forms of the GDST did not differ significantly from a normal distribution. However approximately 20 words were used to discriminate levels of spelling which fell within the lower half of the average range. This suggests that the discrimina- 
TABLE II. Correlations between test scores: normal controls $(n=100)$

\begin{tabular}{|c|c|c|c|c|c|c|c|c|}
\hline & Mat. & Voc. & Nam. & NART & Sch. & Sp. A & Sp. B & Age \\
\hline \multicolumn{9}{|l|}{ Matrices } \\
\hline Vocabulary & $0.34^{* *}$ & & & & & & & \\
\hline Naming & $0.34^{\star \star}$ & $0.66^{\star \star}$ & & & & & & \\
\hline NART & $0.33^{\star \star}$ & $0.77^{\star \star}$ & $0.62^{\star \star}$ & & & & & \\
\hline Schonell & $0.31^{\star *}$ & $0.76^{\star \star}$ & $0.64^{\star \star}$ & $0.90^{\star \star}$ & & & & \\
\hline Spell. A & 0.13 & $0.57^{\star \star}$ & $0.40^{\star \star}$ & $0.75^{\star \star}$ & $0.77^{\star \star}$ & & & \\
\hline Spell. B & 0.14 & $0.57^{\star \star}$ & $0.39^{\star \star}$ & $0.75^{\star \star}$ & $0.75^{\star \star}$ & $0.92^{\star \star}$ & & \\
\hline Age & $-0.51^{\star *}$ & 0.04 & -0.01 & -0.05 & -0.13 & 0.10 & $0.02^{* *}$ & \\
\hline
\end{tabular}

One-tailed level of significance: ${ }^{*} p=0.01 ;{ }^{* *} p=0.001$.

tory value of the test may be better within this band of spelling skills. Alternatively, greater individual differences may exist within those whose spelling skills fall within the lower half of the average range thereby requiring a greater number of items to discriminate between different overall levels.

No significant gender differences were found in this sample (see Table I). The cumulative percentiles for scores on each of the alternative forms of the spelling test and for a combined score $(A+B)$ are given in Appendix 2. The percentile equivalents for raw score bands are given in Appendix 3.

Spearman-rank correlation coefficients were calculated between the scores on the two spelling lists, with age and with the baseline measures (see Table II). Correlations between the scores in the two spelling tests were extremely high, confirming the validity of the two tests as alternative forms. The two forms of the spelling test were highly correlated with the two reading tests. Spelling was moderately correlated with the WAIS Vocabulary subtest and with naming. Scores on the non-verbal reasoning items did not correlate with either spelling tests.

\section{LATERILIZATION STUDY}

\section{Subjects}

A small battery of tests was administered to a consecutive series of patients with unilateral lesions who attended the National Hospital (both in-patients and out-patients). A patient was included if the ward sister judged that the individual was well enough to complete a session of $30-45 \mathrm{~min}$ and they were also able to comprehend the requirements of the tests. Patients were excluded if they had a long-term history of diabetes or epilepsy (unrelated to their lesion) or if they had a history of a head trauma with unconsciousness. Patients were also excluded if they had undergone radiotherapy, if they had a significant degree of deafness or if they had been educated outside the normal English education system.

Unilateral lesions were verified by computerized tomography (CT) scans. There were 26 patients with left hemisphere (LH) lesions and 20 patients with right hemisphere $(\mathrm{RH})$ lesions. Details of the gender distribution and the type of lesion for the two groups are given in Table III.

\section{Procedure}

The battery of tests administered to the RH and LH lesined groups was as follows.

Non-verbal reasoning (Short Matrices). The 20 items taken from the Standard Progressive Matrices, used in the standardization study, were administered.

Verbal skills. The Token Test (De Renzi and Faglioni, 1978) was administered according to standard procedures to obtain an overall measure of verbal impairment for each patient. The WAIS Digit Span subtest was administered according to the standard procedures (Wechsler, 1955) to measure auditory span of attention. Each patient was classified as fluent or non-fluent on the basis of phrase length: a patient was classified as fluent if a sentence of five or more words was produced. The classification was made during the initial 5-10 min conversation which focused on acquiring background information and explaining the purpose of the research. If there was any doubt about this classification, patients were presented with the Cookie Theft Picture from the Boston Aphasia battery (Goodglass and Kaplan, 1972).

Reading skills. The National Adult Reading Test (Nelson, 1983) was presented according to standard procedures.

GDST. The procedure differed from that adopted for the controls in that oral spelling was attempted 
MEASURING DYSGRAPHIA

TABLE III. Characteristics of the lesioned sample

\begin{tabular}{|c|c|c|c|c|c|c|}
\hline \multirow[t]{2}{*}{ Site of lesion } & \multirow{2}{*}{$\begin{array}{c}\text { Age } \\
\text { (years) }\end{array}$} & \multicolumn{2}{|c|}{ Gender } & \multicolumn{3}{|c|}{ Type of lesion } \\
\hline & & Male & Female & Vascular & Tumour & Other* \\
\hline $\begin{array}{l}\text { Left } \\
(n=26)\end{array}$ & $\begin{array}{c}46.5 \\
(13.41)\end{array}$ & 14 & 12 & 7 & 14 & 9 \\
\hline $\begin{array}{l}\text { Right } \\
(n=20)\end{array}$ & $\begin{array}{c}45.80) \\
(13.17)\end{array}$ & 11 & 9 & 6 & 10 & 4 \\
\hline
\end{tabular}

${ }^{\star}$ Abscess, cyst, undiagnosed.

TABLE IV. Differences between the right and left lesion groups on the background tests

\begin{tabular}{|c|c|c|c|}
\hline & $\begin{array}{c}\text { Left } \\
(n=26) \\
x \\
\text { (S.D.) }\end{array}$ & $\begin{array}{c}\text { Right } \\
(n=20) \\
x \\
\text { (S.D.) }\end{array}$ & $M-W$ \\
\hline $\begin{array}{l}\text { Short Matrices } \\
(\text { max. score }=20) \\
\text { NART } \\
(\max . \text { score }=50)\end{array}$ & $\begin{array}{c}11.96 \\
(4.61) \\
19.88 \\
(11.35)\end{array}$ & $\begin{array}{l}11.85 \\
(5.73) \\
30.90 \\
(9.25)\end{array}$ & $\begin{array}{c}z=0.02 \\
p<0.83 \\
z= \\
-1.74 \\
p<0.01\end{array}$ \\
\hline $\begin{array}{l}\text { Token Test } \\
(\max . \text { score }=36)\end{array}$ & $\begin{array}{l}28.12 \\
(7.73)\end{array}$ & $\begin{array}{l}34.45 \\
(1.70)\end{array}$ & $\begin{array}{c}z= \\
-3.09 \\
p<0.01\end{array}$ \\
\hline $\begin{array}{l}\text { Digit Span S.S. } \\
\text { (max. score }=19 \text { ) }\end{array}$ & $\begin{array}{l}8.77 \\
(3.50)\end{array}$ & $\begin{array}{l}11.30 \\
(2.20)\end{array}$ & $\begin{array}{c}z= \\
2.54 \\
p<0.01\end{array}$ \\
\hline
\end{tabular}

M-W, Mann-Whitney U-test.

TABLE V. Differences between the right and left lesion groups on the GDST (Forms $A$ and $B$ )

\begin{tabular}{lccc}
\hline & $\begin{array}{c}\text { Left } \\
(n=26) \\
X\end{array}$ & $\begin{array}{c}\text { Right } \\
(n=20)\end{array}$ & M-W \\
& $($ S.D. $)$ & $\begin{array}{c}X \\
(\text { S.D. })\end{array}$ & \\
& 13.81 & 22.15 & $z=$ \\
Spell A & $(8.35)$ & $(4.36)$ & -3.44 \\
(max. score = 30) & & & $p<0.01$ \\
& 14.15 & 22.60 & $z=$ \\
Spell B & $(9.62)$ & $(4.85)$ & -2.88 \\
(max. score = 30) & & & $p<0.01$ \\
\hline
\end{tabular}

M-W, Mann-Whitney U-test.

on one form and written spelling on the other (the two forms being alternated between these two methods of testing). Additionally, half the patients attempted Form A before Form B and vice versa. Two patients were unable to write because of a hemiplegia and in these cases, as for the normal controls, the examiner wrote the patient's oral spellings in full view and allowed spontaneous corrections in the written condition. Each form of the test was discon- tinued after five consecutive failures, the same criterion as was used for the controls.

\section{RESULTS}

\section{Group comparisons}

Baseline tests. The mean scores and standard deviations for each lesion group on each baseline test are given in Table IV. It is clear from inspection that the RH group's mean score on the NART was superior to that obtained in the standardization study (see Table I). This is a finding obtained in previous group studies conducted at the National Hospital for Neurology and Neurosurgery (e.g. Warrington and James, 1991). It indicates that this group of patients is of above average intelligence and not representative of the population as a whole. Thus a direct comparison with the standardization sample would potentially underestimate the degree of deficit in the $\mathrm{LH}$ lesion group.

A Mann-Whitney U-test comparing the RH and LH lesion groups was computed. The $z$-scores and probability values are given in Table IV. Patients with LH lesions performed at a significantly lower level in all language and literacy skills compared with patients with RH lesions. By contrast there was no significant difference between the two groups in terms of their performance in the Short Matrices Test and thus any differences found in spelling skills cannot be explained by overall differences in their level of nonverbal reasoning.

Spelling tests. The written and oral spelling scores for Form A were summed; similarly the written and oral spelling scores for Form B were summed (in each case half the patients had attempted that form in the written version and vice versa). The mean scores and standard deviations for each lesion group are given in Table V. The LH lesion group scored at a significantly lower level than the $\mathrm{RH}$ lesion group both on Form A and Form B. 


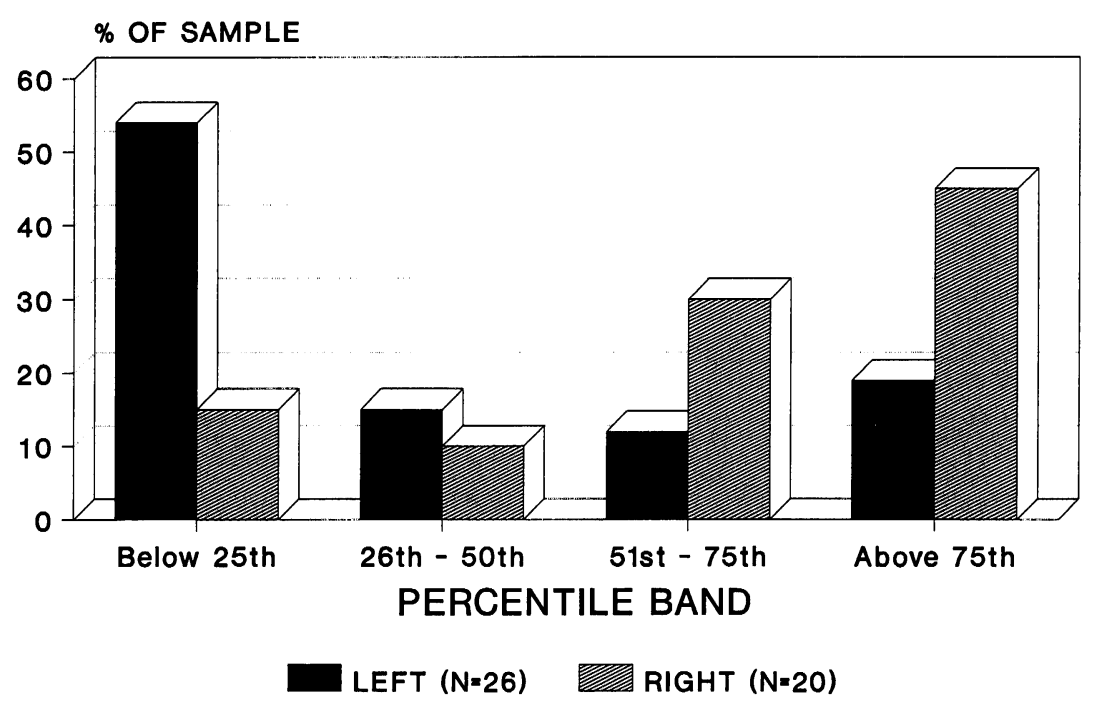

FIG. 1. Percentile distribution, patient samples, Spelling Test $A$.

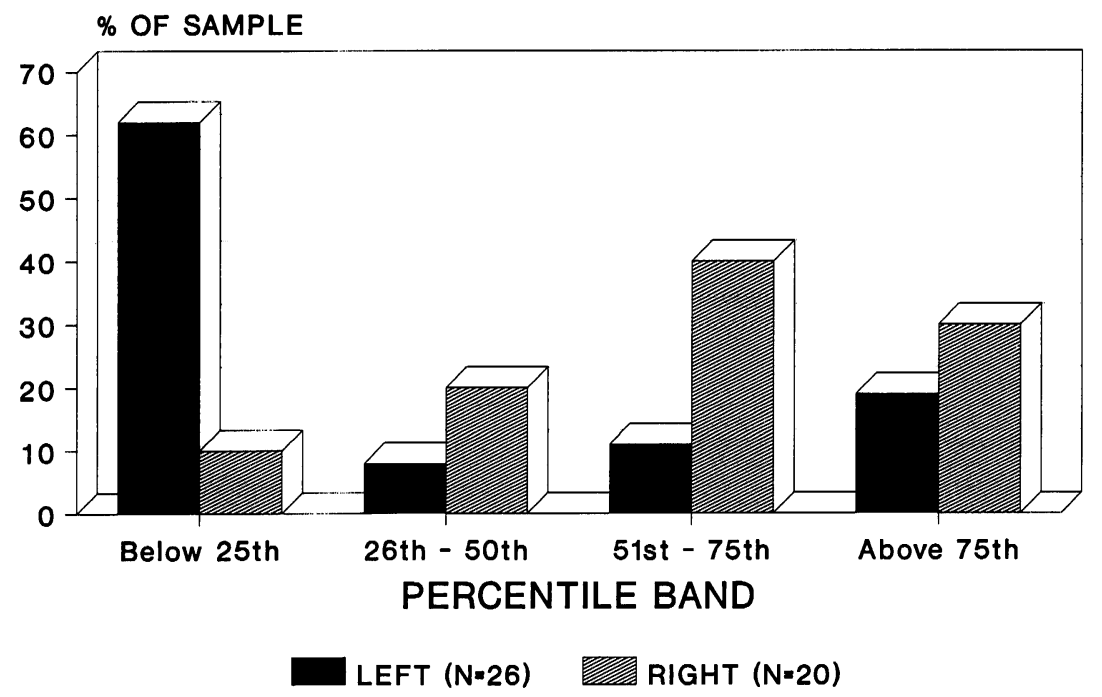

FIG. 2. Percentile distribution, patient samples, Spelling Test B.

A further analysis of the spelling test scores with reference to the standardization scores was computed. A patient's score was allocated to a quartilepercentile band by reference to the percentile scores for the normal population (see Appendix 2). The percentage of $\mathrm{RH}$ and $\mathrm{LH}$ patients scoring in each quartile band is shown in Figs 1 and 2, respectively. The distribution of scores for the RH and LH groups is significantly different in both forms of the spelling test (Form A, $\chi^{2}=9.30, p=0.03$; Form B, $\chi^{2}=$ 13.36, $p<0.01$ ). Eight patients in the LH lesion group scored at or below the 5 th percentile whereas none of the RH lesion scored at this level (see Appen$\operatorname{dix} 4)$.

\section{Individual differences}

Oral and written spelling. There was a high correlation between oral and written spelling in the lesioned groups (Spearman $r=0.90$ ). Only one patient in the RH group had a percentile difference score of more than 25 percentile points between the written and oral spelling conditions. The bias was in favour of oral spelling and qualitative aspects indicated spatial difficulties. No patient in the LH group had such a discrepancy.

Spelling and language skills. The majority of patients whose combined score on the two spelling tests fell at or below the lower 5th percentile had 


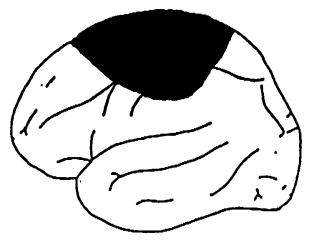

F 60 years. Fronto-parietal cystic lesion.

Spell A+B: $30 \%$ ile. Reading: $81 \%$ ile.

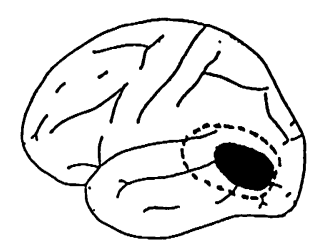

M 63 years.

Posterior temporal-parietal infarct, oedema in parietal lobe.

Spell A+B: 25\%ile.

Reading: $75 \%$ ile.
FIG. 3. Individual patients with specific lexical dysgraphia.

equally impaired scores in the Token Test (6/8). A clear dissociation between the Token Test and spelling was seen in one case who scored well within the impaired range in the Token Test $(24 / 36)$ but whose spelling skills fell at the 90 th percentile. One patient with a score within the normal range on the Token Test $(32 / 36)$ had spelling skills falling within the lower 5th percentile band with equally impaired reading.

A defective score in the Digit Span subtest was invariably associated with spelling scores falling within the lower 5 th percentile band. The reverse was not the case and two patients with spelling scores in this range had average or above average scores in the Digit Span subtest.

Spelling and reading. The majority of patients with spelling scores falling within the lower 25 th percentile band had higher reading scores (13/17). All patients with defective reading scores (four) had spelling scores within the lower quartile and three had additional language deficits (Token Test). Two patients appeared to have selective dysgraphia and showed a discrepancy between their low-average spelling scores and their bright-average reading skills, a percentile difference of 50 points or more. Neither patient had other language impairments and their non-verbal reasoning fell within the average range or above.

Anatomical correlates. The CT scans of the above two patients were plotted according to the method used by Mazzochi and Vignoli (1978) and Luzzati et al. (1979) and are shown in Fig. 3. There was no area of overlap between the lesions of these two patients. It should be noted, however, that the patient with the posterior lesion was investigated more thoroughly by one of the authors and was shown to have residual features of letter-by-letter reading, a feature masked in the group analysis. His reading was slow, but accurate, with evidence of a deterioration in speed when presented with a script as compared with printed material. There was also evidence of a mild deficit in letter selection, characterized by mild peserverative features in written word spelling and a slight bias in favour of oral spelling. In view of these residual deficits, it is likely that the level of impairment within the spelling system was different for the two patients.

\section{DISCUSSION}

In the present study we describe the construction of two alternative forms of an adult GDST and its ability to discriminate between a wide range of different spelling abilities in a cross section of the normal population. Such a range of skills justifies the need for a measurement tool which is able to discriminate between minor degrees of spelling impairment. The GDST provides such an instrument and has the potential for monitoring minor degrees of improvement or decrement in spelling in the adult neurological population.

The two forms of the spelling test (A and B) were found to be highly correlated, thereby fulfilling the requirements of alternative forms. In the normal population, spelling was shown to be highly correlated with reading skills and moderately correlated with vocabulary and other language skills. No significant correlation was found between spelling and non-verbal reasoning as measured by the Short Matrices Test. Neither age nor gender was found to be related to spelling in this "reading-literate" population.

The spelling test was validated in a group of patients with $\mathrm{LH}$ lesions and a group of patients with $\mathrm{RH}$ lesions. There was a general shift of scores in the LH group towards the lower 25th percentile band, with $65 \%$ falling within this band on their combined oral and written spelling. By contrast only $10 \%(n=$ 2) of the RH lesion group had scores falling within the lower quartile. As with other language tests, spelling is a skill lateralized to the left hemisphere.

The majority of patients with impaired spelling had some preservation of reading although impaired reading was invariably associated with comparable levels of spelling difficulty. Thus in this small sample, we observed evidence of only a one-way dissociation, the dissociation of impaired spelling in the presence of intact reading. Although many examples in the literature document the reverse condition, we did not observe such a dissociation in this consecutive sample. It would appear that spelling is the more fragile of the two literacy skills.

Because of the significant correlation between reading and IQ in the general population, reading skills 
are frequently used as a measure of premorbid ability in neurological patients with cognitive impairment. The moderately high correlation between spelling and the WAIS Vocabulary would justify the use of the GDST as an alternative to the frequently used NART to predict premorbid verbal levels in patients who are unable to read aloud because of visual or articulatory problems or those who present with dyslexia without dysgraphia (Dejerine, 1892; Greenblatt, 1973).

As with reading, spelling may be selectively impaired when other language and non-verbal reasoning skills remain intact. Although the most severe spelling impairments were invariably associated with other language deficits, a number of dissociations between spelling and other language-related skills were documented at moderate rather than marked impairments of spelling. Thus two patients with $\mathrm{LH}$ lesions (8\%) were identified as having selective difficulties with spelling in the absence of difficulties with reading and in the context of intact language and non-verbal reasoning skills. The lack of overlap between the CT scans of the two patients with impaired lexical spelling might argue against a single site for this type of spelling dysgraphia. The residual impairment in reading in the one patient might also argue for a further subdivision of this type of dysgraphia with a different level of impairment within the lexical system (and with a different anatomical site).

\section{Acknowledgements}

We are grateful to Dr Marie Midgely and Dr Neil Brooks for help with the SPSS and Harvard Graphics programs and to Merle Galton for the original CT scan plots.

\section{REFERENCES}

Basso A, Taborelli A and Vignolo LA (1978) Dissociated disorders of speaking and writing in aphasia. Journal of Neurology, Neurosurgery and Psychiatry, 41, 556-563.

Baxter DM and Warrington EK (1985) Category specific phonological dysgraphia. Neuropsychologia, 23, 653-666.

Dejerine J (1892) Contribution a l'etude anatomoclinique et clinique des differentes varietes de cecite verbal. Memoires de la Societe de Biologie, 4, 61-90.

De Renzi E and Faglioni P (1978) Normative data and screening power of a shortened version of the Token Test. Cortex, 78, 41-49.

Goodglass H and Geschwind N (1976) Language disorders (aphasia). In: Handbook of Perception, Vol 7 (Eds EC Carterette and MP Friedman). Academic Press, New York.

Goodglass H and Kaplan E (1972) The Assessment of Aphasia and Related Disorders. Lea and Febiger, Philadelphia.

Goodman RA and Caramazzo A (1986) Aspects of the spelling process: evidence from a case of acquired dysgraphia. Language and Cognitive Processes, 1, 263-296.

Greenblatt SH (1973) Alexia without agraphia or hemianopia: anatomical analysis of an autopsied case. Brain, 96, 307-316.

Luzzati G, Scotti G and Gattoni A (1979) Suggestions for cerebral CT-scan localization. Cortex, 15, 483-490.

Mazzochi F and Vignolo LA (1978) Computer assisted tomography on neuropsychological research: a simple procedure for lesion mapping. Cortex, 14, 136-144.

McKenna P and Warrington EK (1983) The Graded Naming Test. The NFER-Nelson Publishing Co., Windsor.

Nelson HE (1983) National Adult Reading Test. The NFER-Nelson Publishing Co., Windsor.

Nelson HE and McKenna P (1975) The use of current reading ability in assessment of dementia. British Journal of Clinical Psychology, 14, 259-267.

Nie NE, Hull CH, Jenkins JG, Steinbrenner K and Bent DH (1975) Statistical Package for the Social Sciences, 2nd edn. McGraw-Hill, Chicago.

Raven JC (1958) Standard Progressive Matrices. H.K. Lewis \& Co., London.

Schonell FJ and Schonell FE (1950) Diagnostic and Attainment Testing. Oliver \& Boyd, Edinburgh.

Shallice T (1981) Phonological agraphia and the lexical route in writing. Brain, 104, 413-429.

Thorndike EL and Lorge I (1944) The Teachers' Word Book of 3,000 Words. Teachers College Press, Columbia University, New York.

Warrington EK and James M (1991) Visual Object Perception Test. Thames Valley Test Co., Reading.

Wechsler D (1955) Manual for the Wechsler Intelligence Scale. The Psychological Corporation, New York.

Weigl E and Fradis A (1977) The transcoding process in patients with agraphia to dictation. Brain and Language, 4, 1-22.

(Received 20 May 1994; accepted as revised 19 October 1994) 
APPENDIX 1. The GDST. Instructions: each word is spoken in the context of a sentence. The target word is given before and after the sentence is spoken. Repetitions of the target word are allowed.

\begin{tabular}{|c|c|}
\hline \multicolumn{2}{|l|}{ Form A } \\
\hline 1. two & I put two books on the desk. \\
\hline 2. world & The world is round. \\
\hline 3. said & I said I would come. \\
\hline 4. shoe & I put my shoe on my foot. \\
\hline 5. case & Bring your coat, in case it rains. \\
\hline 6. flood & $\begin{array}{l}\text { The flood caused damage to the } \\
\text { bridge. }\end{array}$ \\
\hline 7. worse & $\begin{array}{l}\text { The weather is worse than } \\
\text { yesterday. }\end{array}$ \\
\hline 8. sword & He took his sword and went to fight. \\
\hline 9. crawl & Do not crawl on the floor. \\
\hline 10. journey & $\begin{array}{l}\text { They took a long journey across } \\
\text { Asia. }\end{array}$ \\
\hline 11. cruise & $\begin{array}{l}\text { They took a cruise in the } \\
\text { Mediterranean. }\end{array}$ \\
\hline 12. survey & They went to survey the house. \\
\hline 13. boulder & $\begin{array}{l}\text { The rock or boulder fell from the } \\
\text { cliff. }\end{array}$ \\
\hline 14. parachute & The parachute was made of silk. \\
\hline 15. scheme & $\begin{array}{l}\text { The scheme needed a lot of } \\
\text { planning. }\end{array}$ \\
\hline 16. technical & $\begin{array}{l}\text { The lecture was too technical for } \\
\text { the pupil. }\end{array}$ \\
\hline 17. tongue & $\begin{array}{l}\text { The man burned his tongue on the } \\
\text { soup. }\end{array}$ \\
\hline 18. forfeit & $\begin{array}{l}\text { He had to forfeit his turn in the } \\
\text { game. }\end{array}$ \\
\hline 19. plait & She had a long plait in her hair. \\
\hline 20. conceive & $\begin{array}{l}\text { She could not conceive of a } \\
\text { solution. }\end{array}$ \\
\hline 21. languid & $\begin{array}{l}\text { He felt weak and languid after } \\
\text { sunbathing. }\end{array}$ \\
\hline 22. column & $\begin{array}{l}\text { The column was decorated with } \\
\text { many carvings. }\end{array}$ \\
\hline 23. gaudy & $\begin{array}{l}\text { The gaudy, multi-coloured dress } \\
\text { caused quite a stir. }\end{array}$ \\
\hline 24. epilogue & $\begin{array}{l}\text { After the epilogue, they turned off } \\
\text { their T.V. }\end{array}$ \\
\hline 25. moustache & $\begin{array}{l}\text { His moustache curled up at the } \\
\text { ends. }\end{array}$ \\
\hline 26. trafficking & $\begin{array}{l}\text { The man was caught trafficking } \\
\text { drugs. }\end{array}$ \\
\hline 27. privilege & $\begin{array}{l}\text { It was a great privilege to meet the } \\
\text { minister. }\end{array}$ \\
\hline 28. cemetery & $\begin{array}{l}\text { The cemetery was neat and full of } \\
\text { flowers. }\end{array}$ \\
\hline 29. kaleidoscope & $\begin{array}{l}\text { She was given a kaleidoscope for } \\
\text { Christmas. }\end{array}$ \\
\hline 30. iridescent & $\begin{array}{l}\text { The lamp gave the garden an irides- } \\
\text { cent glow. }\end{array}$ \\
\hline
\end{tabular}

\begin{tabular}{|c|c|}
\hline \multicolumn{2}{|l|}{ Form B } \\
\hline 1. again & Do come again, if you wish. \\
\hline 2. base & The plane landed at its home base. \\
\hline 3. folk & The guitarist played folk music. \\
\hline 4. once & They went to the cafe once a week. \\
\hline 5. people & The people cheered the winner. \\
\hline 6. skirt & She put a pleat in her skirt. \\
\hline 7. sure & Are you sure you let the cat out? \\
\hline 8. weight & What is the weight of the parcel? \\
\hline 9. wreck & $\begin{array}{l}\text { The ship was a wreck after the } \\
\text { storm. }\end{array}$ \\
\hline 10. caught & He caught the ball with one hand. \\
\hline 11. bruise & She had a bruise on her knee. \\
\hline 12. survive & $\begin{array}{l}\text { He managed to survive with little } \\
\text { money. }\end{array}$ \\
\hline 13. smoulder & $\begin{array}{l}\text { The fire will smoulder if it is not put } \\
\text { out. }\end{array}$ \\
\hline 14. journal & $\begin{array}{l}\text { The article was published in a well- } \\
\text { known journal. }\end{array}$ \\
\hline 15. debut & $\begin{array}{l}\text { She made her debut at a London } \\
\text { theatre. }\end{array}$ \\
\hline 16. mechanical & The car had a mechanical fault. \\
\hline 17. gauze & The nurse put gauze on the wound. \\
\hline 18. stirrup & $\begin{array}{l}\text { The stirrup slipped and caused the } \\
\text { rider to fall. }\end{array}$ \\
\hline 19. mongrel & $\begin{array}{l}\text { The mongrel was their favourite } \\
\text { dog. }\end{array}$ \\
\hline 20. scissors & $\begin{array}{l}\text { The scissors were blunt and did not } \\
\text { cut the cloth. }\end{array}$ \\
\hline 21. deceive & He could never deceive his mother. \\
\hline 22. yacht & $\begin{array}{l}\text { He bought a yacht for his } \\
\text { retirement. }\end{array}$ \\
\hline 23. prologue & $\begin{array}{l}\text { The prologue introduced the charac- } \\
\text { ters in the play. }\end{array}$ \\
\hline 24. pursuit & $\begin{array}{l}\text { They went in hot pursult of the runa- } \\
\text { way horse. }\end{array}$ \\
\hline 25. referred & $\begin{array}{l}\text { She was referred to a specialist for } \\
\text { her back. }\end{array}$ \\
\hline 26. suave & $\begin{array}{l}\text { The young man looked very suave } \\
\text { in his new suit. }\end{array}$ \\
\hline 27. prejudice & $\begin{array}{l}\text { It was prejudice that stopped her } \\
\text { liking the girl. }\end{array}$ \\
\hline 28. buoyant & $\begin{array}{l}\text { Women are meant to be more buoy- } \\
\text { ant than men. }\end{array}$ \\
\hline nicking & They went picnicking in the park. \\
\hline 30. & $\begin{array}{l}\text { The pharaoh was famous through- } \\
\text { out the land. }\end{array}$ \\
\hline
\end{tabular}


APPENDIX 2. Cumulative frequencies (percentiles) on the GDST: Forms A, B and A + B

\begin{tabular}{|c|c|c|c|c|c|c|}
\hline Score & $\begin{array}{c}A \\
\text { (\%ile) }\end{array}$ & $\begin{array}{c}B \\
\text { (\%ile) }\end{array}$ & Score & $\begin{array}{l}A+B \\
\text { (\%ile) }\end{array}$ & Score & $\begin{array}{l}A+B \\
\text { (\%ile) }\end{array}$ \\
\hline 1 & & 1 & 1 & & 31 & 22 \\
\hline 2 & & & 2 & & 32 & 23 \\
\hline 3 & & 2 & 3 & & 33 & \\
\hline 4 & 1 & 3 & 4 & & 34 & 24 \\
\hline 5 & & 5 & 5 & 1 & 35 & 27 \\
\hline 6 & 4 & 7 & 6 & & 36 & 29 \\
\hline 7 & 7 & 9 & 7 & & 37 & 32 \\
\hline 8 & 8 & & 8 & & 38 & 39 \\
\hline 9 & 9 & 10 & 9 & 2 & 39 & 42 \\
\hline 10 & 11 & 11 & 10 & & 40 & 46 \\
\hline 11 & 12 & & 11 & 3 & 41 & 52 \\
\hline 12 & 15 & 12 & 12 & 5 & 42 & 54 \\
\hline 13 & 16 & 15 & 13 & 7 & 43 & 56 \\
\hline 14 & 19 & 16 & 14 & 8 & 44 & 61 \\
\hline 15 & 21 & 20 & 15 & & 45 & 65 \\
\hline 16 & 24 & 24 & 16 & & 46 & 67 \\
\hline 17 & 29 & 25 & 17 & 9 & 47 & 68 \\
\hline 18 & 37 & 31 & 18 & & 48 & 72 \\
\hline 19 & 40 & 37 & 19 & & 49 & 74 \\
\hline 20 & 49 & 46 & 20 & & 50 & 79 \\
\hline 21 & 55 & 53 & 21 & 10 & 51 & 84 \\
\hline 22 & 61 & 61 & 22 & 12 & 52 & 86 \\
\hline 23 & 70 & 67 & 23 & & 53 & 92 \\
\hline 24 & 78 & 70 & 24 & 14 & 54 & 95 \\
\hline 25 & 82 & 79 & 25 & & 55 & 99 \\
\hline 26 & 90 & 86 & 26 & 15 & 56 & 100 \\
\hline 27 & 96 & 96 & 27 & 16 & 57 & \\
\hline 28 & 100 & 99 & 28 & 17 & 58 & \\
\hline 29 & & 100 & 29 & 10 & 59 & \\
\hline 30 & & & 30 & & 60 & \\
\hline
\end{tabular}

Normal sample, $n=100$.

APPENDIX 3. Conversion of raw scores to percentile equivalents on the GDST- Forms A, B and A + B

\begin{tabular}{cccr}
\hline$\%$ ile & $\begin{array}{c}\text { A } \\
\text { score }\end{array}$ & $\begin{array}{c}\text { B } \\
\text { score }\end{array}$ & $\begin{array}{r}\text { A + B } \\
\text { score }\end{array}$ \\
\hline $96+$ & $28+$ & $28+$ & $55+$ \\
$91-95$ & 27 & 27 & $53-54$ \\
$76-90$ & $25-26$ & $25-26$ & $50-52$ \\
$51-75$ & $21-24$ & $21-24$ & $41-49$ \\
$26-50$ & $17-20$ & $18-20$ & $35-40$ \\
$11-25$ & $10-16$ & $10-17$ & $22-34$ \\
$6-10$ & $7-9$ & $6-9$ & $13-21$ \\
$0-5$ & $0-6$ & $0-5$ & $0-12$ \\
\hline
\end{tabular}

Normal sample, $n=100$.
APPENDIX 4. Number of patients with left (L) or right (R) hemisphere lesions with scores falling at or below the fifth percentile in the GDST (Forms $A+B$ )

\begin{tabular}{ccc}
\hline$\%$ ile & L & R \\
\hline $0-5$ & 8 & 0 \\
$6-25$ & 8 & 2 \\
$26-50$ & 2 & 4 \\
$51-75$ & 3 & 8 \\
$76+$ & 5 & 6 \\
\hline
\end{tabular}




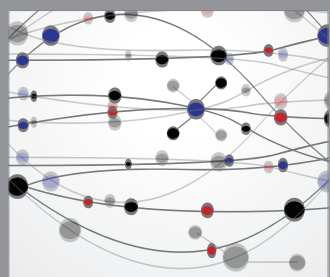

The Scientific World Journal
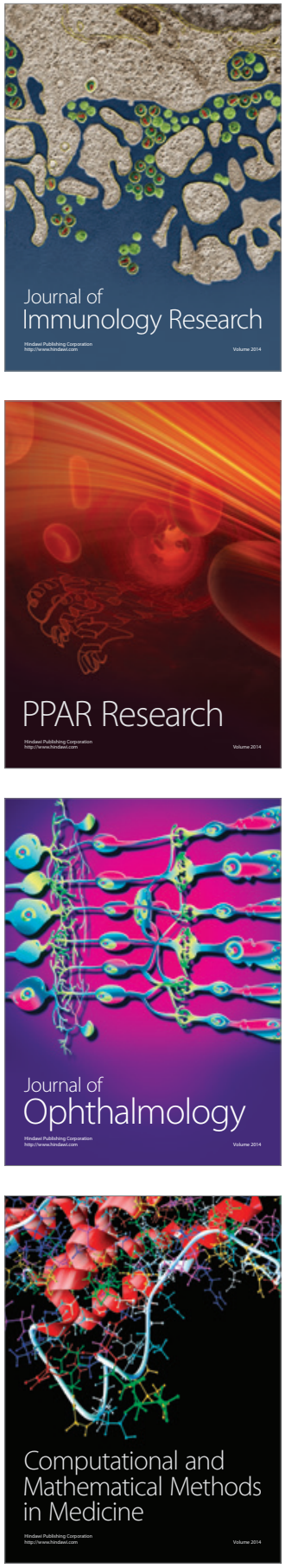

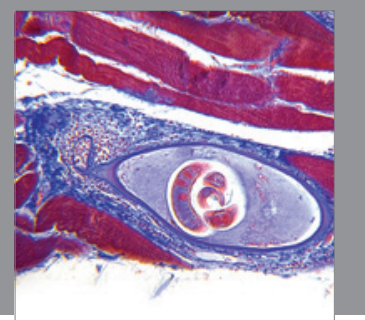

Gastroenterology

Research and Practice
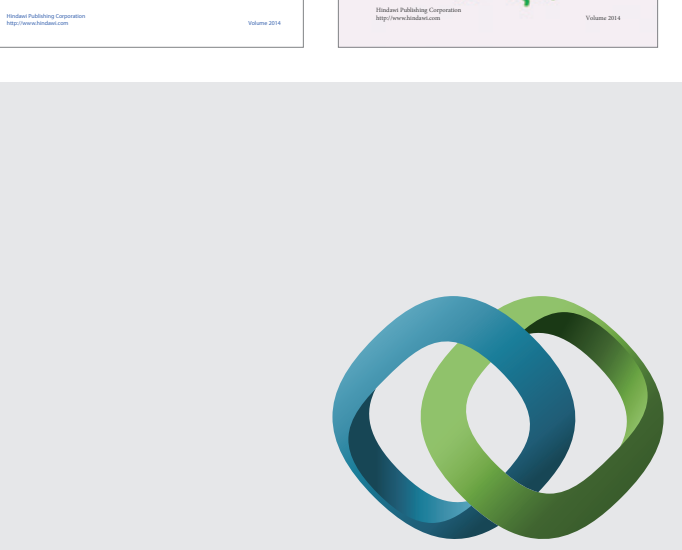

\section{Hindawi}

Submit your manuscripts at

http://www.hindawi.com
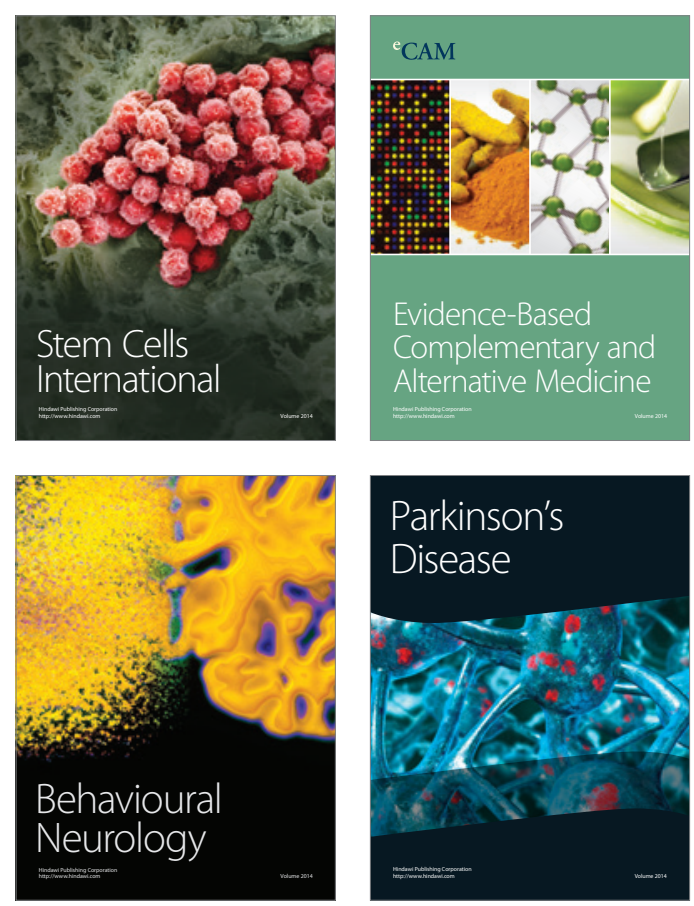

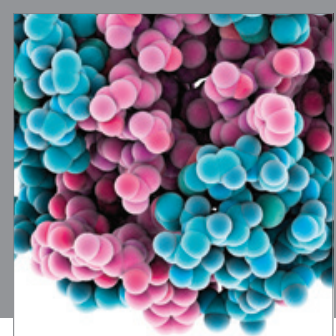

Journal of
Diabetes Research

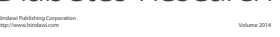

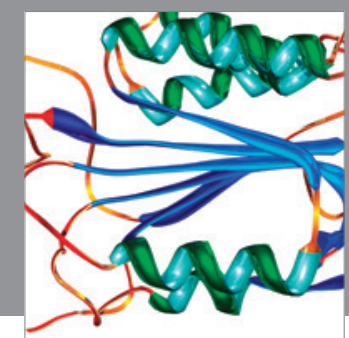

Disease Markers
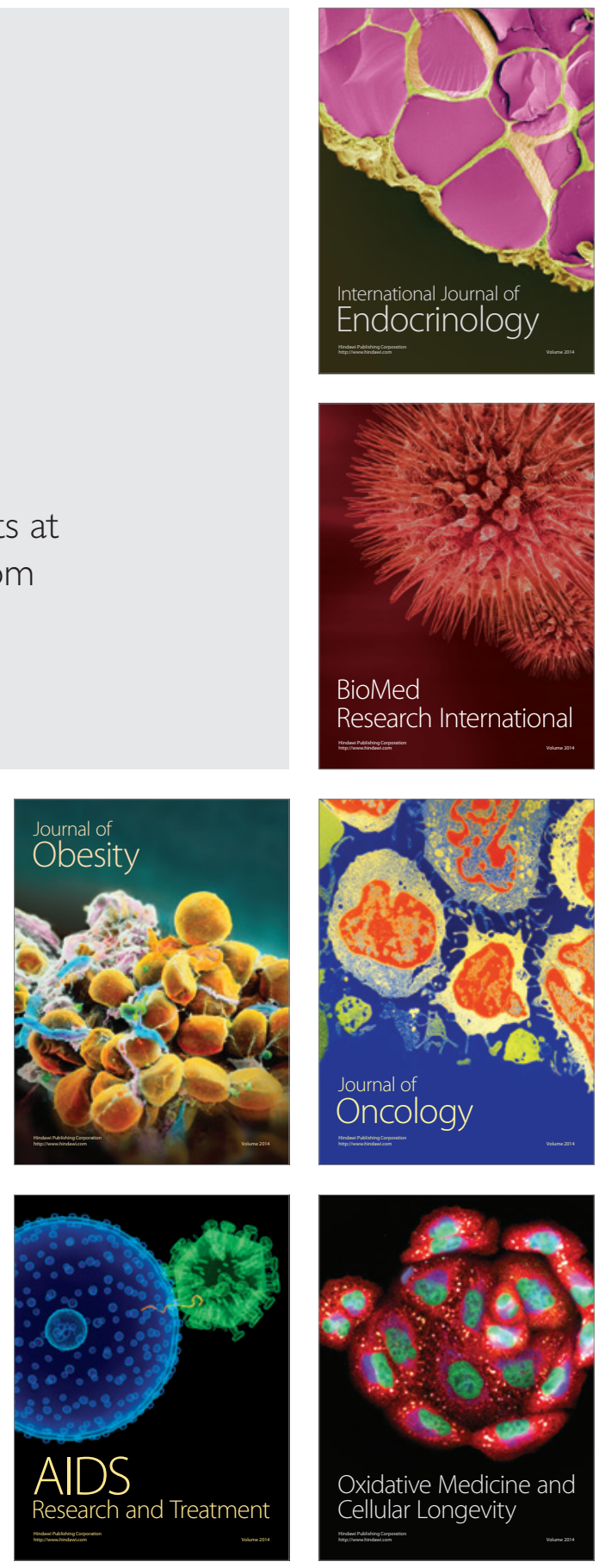